\title{
Yaequinolones, New Insecticidal Antibiotics Produced by Penicillium sp. FKI-2140
}

\author{
II. Structural Elucidation
}

\author{
Ryuji Uchida, Rie Imasato, Hiroshi Tomoda, Satoshi Ōmura
}

Received: June 29, 2006 / Accepted: October 9, 2006

(C) Japan Antibiotics Research Association

\begin{abstract}
The structure and relative stereochemistry of yaequinolones, fungal insecticidal antibiotics, were elucidated by spectroscopic studies, including NMR spectral analyses. Yaequinolones possess a $p$-methoxyphenylquinolinone skeleton modified with different isoprenyl-derived side chains.
\end{abstract}

Keywords yaequinolone, insecticide, fungal metabolites, structural elucidation, Penicillium sp., $p$-methoxyphenylquinolinone

\section{Introduction}

Yaequinolones and structurally related compounds $(\mathbf{1} \sim \mathbf{1 6}$, Fig. 1) were isolated from the culture broth of Penicillium sp. FKI-2140 as insecticidal antibiotics against brine shrimp (Artemia salina). The fermentation, isolation and biological activity were described in the preceding paper [1]. In this study, we describe the elucidation of the structure of $1 \sim 7$ and show that these compounds possess a quinolinone core with a variety of isoprenyl-derived side chains. In progress of this study, compounds $\mathbf{1}$ and $\mathbf{2}$ were identified as $3 R^{*}, 4 S^{*}$-dihydroxy-3,4-dihydro-4-(4' methoxyphenyl)-2(1H)-quinolinone and $3 R^{*}, 4 R^{*}$-dihydroxy3,4-dihydro-4-(4'-methoxyphenyl)-2(1H)-quinolinone [3], respectively. The structural elucidation of $\mathbf{8}$ and $\mathbf{9}$, having a $p$-methoxyphenylquinolinone skeleton fused with an

H. Tomoda (Corresponding author), R. Uchida: School of Pharmacy, Kitasato University, 5-9-1 Shirokane, Minato-ku, Tokyo 108-8641, Japan, E-mail: tomodah@pharm.kitasato-u.ac.jp isoprenyl pyran ring, was reported elsewhere [2].

\section{Results}

\section{Structural Elucidation}

The physico-chemical properties and ${ }^{1} \mathrm{H}$ and ${ }^{13} \mathrm{C}$ NMR data of 1 to 7 are summarized in Tables 1,2 and $3 .{ }^{1} \mathrm{H}$ and ${ }^{13} \mathrm{C}$ NMR data of $\mathbf{1 3}$ and $\mathbf{1 4}$ are also shown for comparison. From the MS, ${ }^{1} \mathrm{H}$ and ${ }^{13} \mathrm{C}$ NMR (data not shown), 10 to 16 were identified as 4-hydroxy-3,4-dihydro-3-methoxy4-(4'-methoxyphenyl)-2(1H)-quinolinone (quinolinone A, 10) [4], 4,5-dihydroxy-3,4-dihydro-3-methoxy-4-(4' methoxyphenyl)-2(1H)-quinolinone (quinolinone $\mathrm{B}, \mathbf{1 1}$ ) [4], peniprequinolone (12) [5], penigequinolones $\mathrm{A}$ and $\mathrm{B}$ $(\mathbf{1 3}, \mathbf{1 4})[5,6], 4^{\prime}$-methoxycyclopeptin (15) [5] and transdehydro-4'-methoxycyclopeptin (16) [7]. Compounds 1 and 2 were named yaequinolones A1 and A2 in this study, therefore these structural elucidations were described blow.

Yaequinolones A1 (1) and A2 (2): The molecular formulas of $\mathbf{1}$ and $\mathbf{2}$ were revealed to be $\mathrm{C}_{16} \mathrm{H}_{15} \mathrm{NO}_{4}$ by HRFAB-MS, thus requiring 10 degrees of unsaturation. The similarity in the ${ }^{13} \mathrm{C}$ NMR spectra (Table 3 ) of $\mathbf{1}$ and $\mathbf{2}$ strongly suggested that they have the same planar structure. The ${ }^{13} \mathrm{C}$ NMR spectra of $\mathbf{1}$ and $\mathbf{2}$ showed 16 carbons, which were classified into 1 methyl, $8 s p^{2}$ methine, $1 s p^{3}$ methine, and 6 quaternary carbons by analysis of the DEPT spectra. The connectivity of proton and carbon atoms was

R. Imasato, S. Ōmura: Kitasato Institute for Life Sciences, \& Graduate School of Infection Control Sciences, Kitasato University and The Kitasato Institute, 5-9-1 Shirokane, Minatoku, Tokyo 108-8641, Japan 


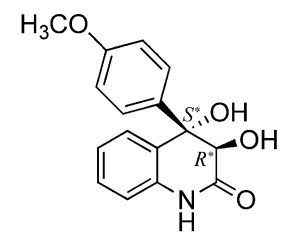

Yaequinolone A1 (1)
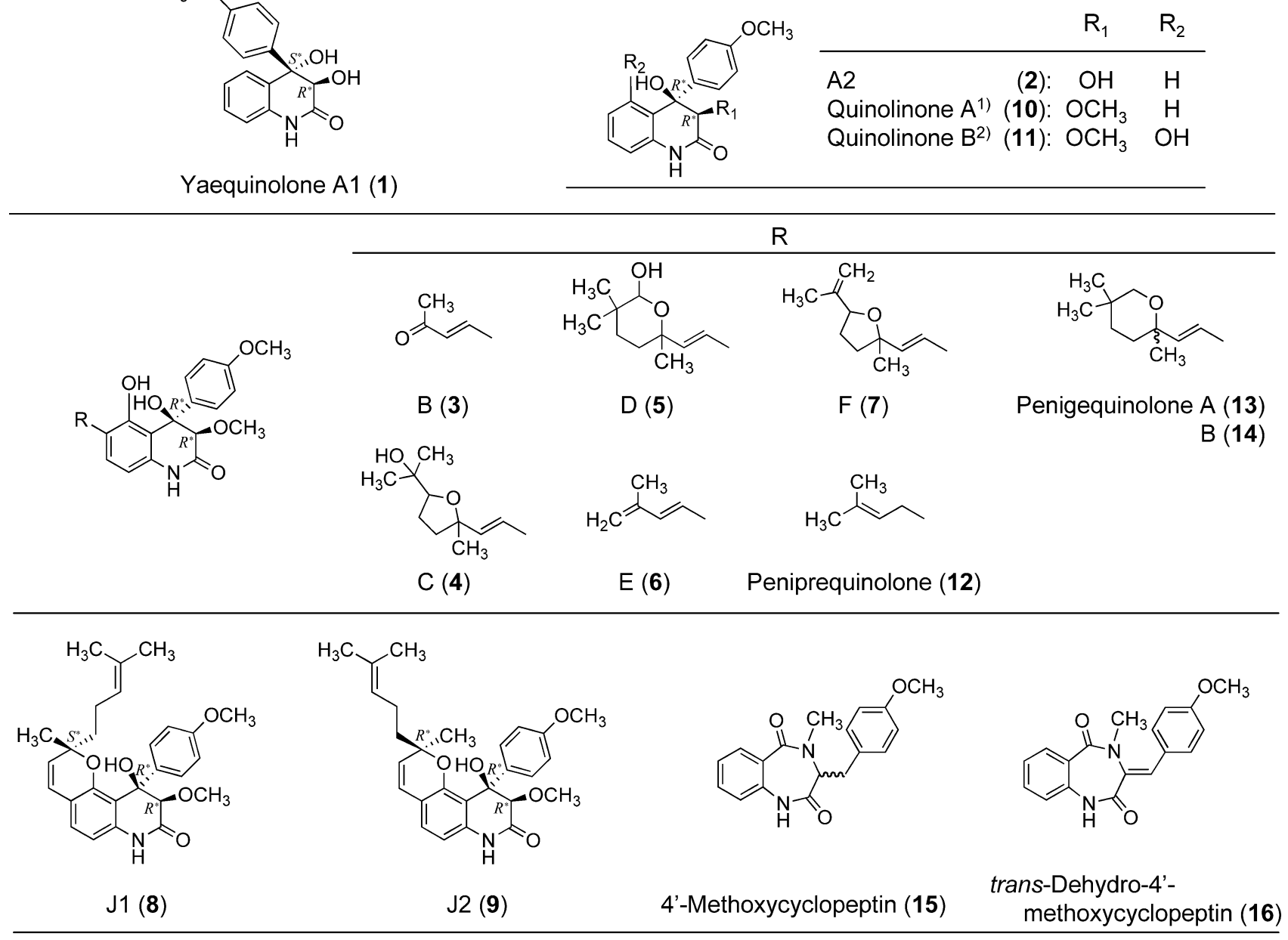

Fig. 1 Structures of yaequinolones and related compounds.

1) Quinolinone A: 4-Hydroxy-3,4-dihydro-3-methoxy-4-(4'-methoxyphenyl)-2(1H)-quinolinone. 2) Quinolinone B: 4,5-Dihydroxy-3,4dihydro-3-methoxy-4-(4'-methoxyphenyl)-2(1 H)-quinolinone.

established according to the HMQC spectra. As shown by the bold lines for $\mathbf{1}$ and $\mathbf{2}$ in Fig. 2, a partial structure I $(-\mathrm{CH}=\mathrm{CH}-\mathrm{CH}=\mathrm{CH}-)$ and two partial structures II $(-\mathrm{CH}=\mathrm{CH}-)$ become clear from the ${ }^{1} \mathrm{H}-{ }^{1} \mathrm{H}$ COSY spectra. The ${ }^{13} \mathrm{C}-{ }^{1} \mathrm{H}$ long-range couplings of ${ }^{2} J$ and ${ }^{3} J$ in the HMBC spectra (Fig. 2) proved the following linkages. 1) The longrange couplings from $\mathrm{H} 5(\delta$ 7.68) to $\mathrm{C} 8 \mathrm{a}(\delta 133.4)$ and from $\mathrm{H} 8(\delta 6.85)$ to $\mathrm{C} 4 \mathrm{a}(\delta$ 130.3) suggested the presence of a 1,2-disubstituted benzene ring containing the partial structure I. 2) The long range couplings from $\mathrm{H}^{\prime}\left(\mathrm{H}^{\prime}\right)(\delta$ $7.21)$ to $\mathrm{C}^{\prime}(\delta 159.5)$ and from $\mathrm{H}^{\prime}\left(\mathrm{H}^{\prime}\right)(\delta 6.73)$ to $\mathrm{C}^{\prime}{ }^{\prime}$ ( $\delta$ 131.6) suggested the presence of a 1,4-disubstituted benzene ring containing the two partial structures II. Furthermore, long-range coupling was observed from oxymethyl proton $4^{\prime}-\mathrm{OCH}_{3}(\delta 3.71)$ to $\mathrm{C}^{\prime}$ ', indicating that this benzene ring is a $p$-methoxyphenyl group. 3) The longrange couplings from $\mathrm{H} 3(\delta 4.72)$ to $\mathrm{C} 4(\delta 77.1), \mathrm{C} 4 \mathrm{a}, \mathrm{C} 2$
( $\delta$ 170.7) and $\mathrm{C} 1^{\prime}$ and from $\mathrm{H} 5$ and $\mathrm{H}^{\prime}\left(\mathrm{H}^{\prime}\right)$ to $\mathrm{C} 4$ suggested that the $p$-methoxyphenyl group is attached to C4. 4) The presence of an amide group $\left(\delta_{\mathrm{H}} 8.07, \delta_{\mathrm{C}} 170.7\right)$ was indicated by the NMR data. Considering the degree of unsaturation, it was thought that a quinolinone ring was formed from the disubstituted benzene ring and the amide group. Furthermore, considering the molecular formula, the two remaining protons should exist as two hydroxy groups at $\mathrm{C} 3$ and $\mathrm{C} 4$ of the quinolinone ring. Thus, identical planar structures were elucidated for $\mathbf{1}$ and $\mathbf{2}$, as shown in Fig. 2.

Yaequinolone B (3): The molecular formula of $\mathbf{3}$ was determined to be $\mathrm{C}_{21} \mathrm{H}_{21} \mathrm{NO}_{6}$ by HR-FAB-MS. The ${ }^{1} \mathrm{H}$ and ${ }^{13} \mathrm{C}$ NMR spectra (Tables 2 and 3 ) resembled those of 2 except for the carbon signals of $\mathrm{C} 3, \mathrm{C} 5$ and $\mathrm{C} 6$. The differences are explained below. As shown by the bold lines for 3 in Fig. 2, the partial structure III $(-\mathrm{CH}=\mathrm{CH}-)$ became clear from the ${ }^{1} \mathrm{H}^{-}{ }^{1} \mathrm{H}$ COSY spectra, and the coupling 
Table 1 Physico-chemical properties of yaequinolones 1 to 7

\begin{tabular}{|c|c|c|c|c|}
\hline & 1 & 2 & 3 & 4 \\
\hline Appearance & Pale yellow powder & Pale yellow powder & Pale yellow powder & Pale yellow powder \\
\hline Molecular weight & 285 & 285 & 383 & 483 \\
\hline $\begin{array}{l}\text { Molecular formula } \\
\text { HRFAB-MS }\end{array}$ & $\mathrm{C}_{16} \mathrm{H}_{15} \mathrm{NO}_{4}$ & $\mathrm{C}_{16} \mathrm{H}_{15} \mathrm{NO}_{4}$ & $\mathrm{C}_{21} \mathrm{H}_{21} \mathrm{NO}_{6}$ & $\mathrm{C}_{27} \mathrm{H}_{33} \mathrm{NO}_{7}$ \\
\hline calcd & $308.0899(\mathrm{M}+\mathrm{Na})^{+}$ & $308.0899(\mathrm{M}+\mathrm{Na})^{+}$ & $382.1291(\mathrm{M}-\mathrm{H})^{-}$ & $483.2257(\mathrm{M})^{+}$ \\
\hline found & $308.0888(\mathrm{M}+\mathrm{Na})^{+}$ & $308.0884(\mathrm{M}+\mathrm{Na})^{+}$ & $382.1306(\mathrm{M}-\mathrm{H})^{-}$ & $483.2265(\mathrm{M})^{+}$ \\
\hline$U V \lambda_{\max }^{\mathrm{EtOH}} \mathrm{nm}(\varepsilon)$ & $\begin{array}{l}209(40,800), 226(19,200), \\
250(12,700), 280(4,600)\end{array}$ & $\begin{array}{l}208(43,000), 227(18,900) \\
250(11,300), 283(5,100)\end{array}$ & $\begin{array}{l}228(15,600), 334(7,900) \\
357(8,900)\end{array}$ & $\begin{array}{l}220(25,900), 279(13.800), \\
290(10,400) 324(12,900)\end{array}$ \\
\hline $\mathrm{IR} v_{\max }^{\mathrm{KBr}} \mathrm{cm}^{-1}$ & $\begin{array}{l}3426,2910,1683,1606 \\
1508,1301,1247,1178, \\
1137,1027,759\end{array}$ & $\begin{array}{l}3253,2925,1689,1602 \\
1509,1380,1253,1174 \\
1081,1033,811,769\end{array}$ & $\begin{array}{l}\text { 3428, 2925, 1629, 1259, } \\
\text { 1031, } 806\end{array}$ & $\begin{array}{l}3315,2964,1689,1608 \\
1509,1378,1257,1172 \\
1081,1033,806\end{array}$ \\
\hline$[\alpha]_{D}^{23}(\mathrm{EtOH})$ & $-32.2(c 0.1)$ & $-50.9(c 0.1)$ & $+41.2(c 0.1)$ & $+32.4(c 0.1)$ \\
\hline \multicolumn{5}{|l|}{ Solubility } \\
\hline soluble & $\begin{array}{l}\mathrm{CHCl}_{3}, \mathrm{MeOH} \text {, Acetone, } \\
\text { EtOAc, DMSO }\end{array}$ & $\begin{array}{l}\mathrm{CHCl}_{3}, \mathrm{MeOH} \text {, Acetone, } \\
\text { EtOAc, DMSO }\end{array}$ & $\begin{array}{l}\mathrm{CHCl}_{3}, \mathrm{MeOH}, \text { Acetone, } \\
\text { EtOAc, DMSO }\end{array}$ & $\begin{array}{l}\mathrm{CHCl}_{3}, \mathrm{MeOH} \text {, Acetone, } \\
\text { EtOAc, DMSO }\end{array}$ \\
\hline \multirow[t]{2}{*}{ insoluble } & Hexane, $\mathrm{H}_{2} \mathrm{O}$ & Hexane, $\mathrm{H}_{2} \mathrm{O}$ & Hexane, $\mathrm{H}_{2} \mathrm{O}$ & Hexane, $\mathrm{H}_{2} \mathrm{O}$ \\
\hline & \multicolumn{4}{|l|}{5} \\
\hline Appearance & Pale yellow powder & Pale yellow powder & Pale yellow powder & \\
\hline Molecular weight & 483 & 381 & 465 & \\
\hline $\begin{array}{l}\text { Molecular formula } \\
\text { HRFAB-MS }\end{array}$ & $\mathrm{C}_{27} \mathrm{H}_{33} \mathrm{NO}_{7}$ & $\mathrm{C}_{22} \mathrm{H}_{23} \mathrm{NO}_{5}$ & $\mathrm{C}_{27} \mathrm{H}_{31} \mathrm{NO}_{6}$ & \\
\hline calcd & $506.2155(\mathrm{M}+\mathrm{Na})^{+}$ & $381.1576(\mathrm{M})^{+}$ & $465.2151(\mathrm{M})^{+}$ & \\
\hline found & $506.2156(\mathrm{M}+\mathrm{Na})^{+}$ & $381.1574(\mathrm{M})^{+}$ & $465.2151(\mathrm{M})^{+}$ & \\
\hline UV $\lambda_{\max }^{\mathrm{EtOH}} \mathrm{nm}(\varepsilon)$ & $\begin{array}{l}221(20,700), 279(12,600) \\
288(9,500), 324(10,700)\end{array}$ & $\begin{array}{l}223(18,800), 280(8,400) \\
291(8,300), 324(6,800)\end{array}$ & $\begin{array}{l}219(20,600), 279(11,800) \\
287(9,100), 324(10,800)\end{array}$ & \\
\hline $\mathrm{IR} v_{\max }^{\mathrm{KBr}} \mathrm{cm}^{-1}$ & $\begin{array}{l}3428,2937,1687,1610 \\
1511,1378,1257,1176 \\
1072,1033,825\end{array}$ & $\begin{array}{l}2937,1687,1600,1255 \\
1174,1076,1037,823\end{array}$ & $\begin{array}{l}3426,2925,1689,1608 \\
\text { 1461, 1261, 1093, 1031, } \\
806\end{array}$ & \\
\hline $\begin{array}{l}{[\alpha]_{D}^{23}(\mathrm{EtOH})} \\
\text { Solubility }\end{array}$ & $+56.1(c 0.1)$ & $+51.2(c 0.1)$ & $+76.9(c 0.1)$ & \\
\hline soluble & $\begin{array}{l}\mathrm{CHCl}_{3}, \mathrm{MeOH} \text {, Acetone, } \\
\text { EtOAc, DMSO }\end{array}$ & $\begin{array}{l}\mathrm{CHCl}_{3}, \mathrm{MeOH} \text {, Acetone, } \\
\text { EtOAc, DMSO }\end{array}$ & $\begin{array}{l}\mathrm{CHCl}_{3}, \mathrm{MeOH}, \text { Acetone, } \\
\text { EtOAc, DMSO }\end{array}$ & \\
\hline insoluble & Hexane, $\mathrm{H}_{2} \mathrm{O}$ & Hexane, $\mathrm{H}_{2} \mathrm{O}$ & Hexane, $\mathrm{H}_{2} \mathrm{O}$ & \\
\hline
\end{tabular}

constant $(16.5 \mathrm{~Hz})$ observed between $\mathrm{H} 1{ }^{\prime \prime}(\delta 7.80)$ and $\mathrm{H} 2^{\prime \prime}$ $(\delta 6.70)$ indicated that these olefin protons are oriented in the trans position. According to HMBC experiments, the cross peaks from $\mathrm{H}^{\prime \prime}$ and $\mathrm{H}_{3} 4^{\prime \prime}\left(\delta\right.$ 2.35) to $\mathrm{C}^{\prime \prime}$ ( $\delta$ 199.4) showed the presence of an (E)-3-oxo-1-butenyl group containing the partial structure III. Furthermore, the cross peaks from $\mathrm{H} 7(\delta 7.50)$ to $\mathrm{C}^{\prime \prime}$ ( $\delta$ 138.1), from $\mathrm{H}^{\prime \prime}$ to $\mathrm{C} 7$ $(\delta 129.7)$ and from $\mathrm{H} 2 "$ to $\mathrm{C} 6(\delta 119.3)$ indicated that the (E)-3-oxo-1-butenyl group is attached to C6. The cross peaks from the methoxy protons of $3-\mathrm{OCH}_{3}(\delta 3.62)$ to $\mathrm{C} 3$ $(\delta$ 84.0) and from $\mathrm{H} 3(\delta 3.72)$ to the methoxy carbon $(\delta$ $59.7)$, indicated that the methoxy group is connected to $\mathrm{C} 3$.
Finally, the cross peaks from $\mathrm{OH} 5$ ( $\delta 9.45)$ to $\mathrm{C} 5$ ( $\delta 157.4)$ and $\mathrm{C} 6$ indicated the hydroxy group exists at $\mathrm{C} 5$. Thus, the planar structure for $\mathbf{3}$ was elucidated to be that shown in Fig. 2, which satisfied the molecular formula.

Yaequinolone $\mathrm{C}$ (4): The molecular formula of 4 was determined to be $\mathrm{C}_{27} \mathrm{H}_{33} \mathrm{NO}_{7}$ by HR-FAB-MS, thus requiring 12 degrees of unsaturation. The ${ }^{1} \mathrm{H}$ and ${ }^{13} \mathrm{C}$ NMR spectra (Tables 2 and 3) resembled those of $\mathbf{1 3}$ or $\mathbf{1 4}$ except for the carbon signals of the tetrahydropyran ring. As shown by the bold lines for $\mathbf{4}$ in Fig. 2, the partial structure IV $\left(-\mathrm{CH}_{2}-\mathrm{CH}_{2}-\mathrm{CH}-\right)$ became clear from the ${ }^{1} \mathrm{H}-{ }^{1} \mathrm{H} \mathrm{COSY}$ spectrum. According to $\mathrm{HMBC}$ experiments, the cross 


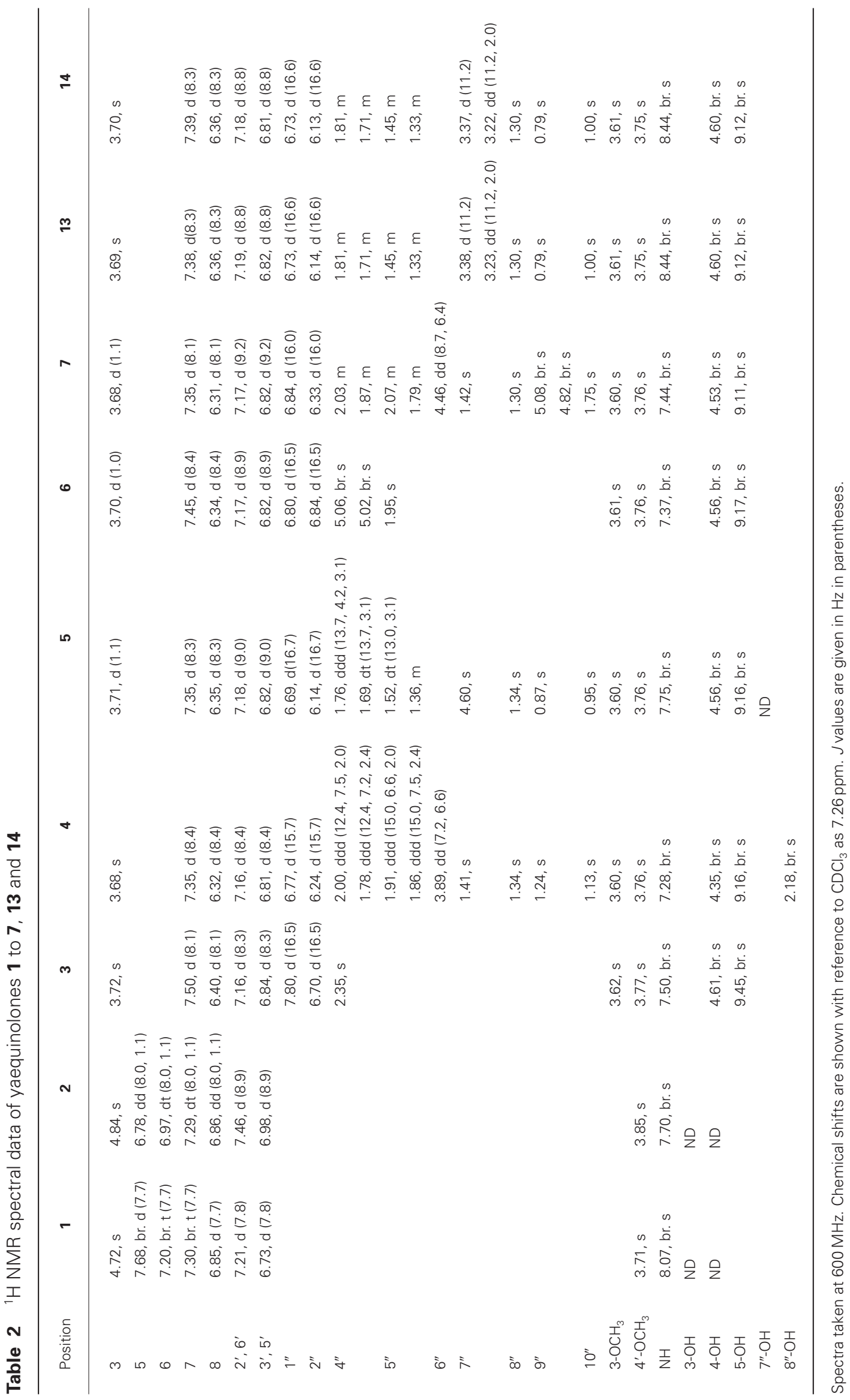


Table $3 \quad{ }^{13} \mathrm{C}$ NMR spectral data of yaequinolones $\mathbf{1}$ to $\mathbf{7}, \mathbf{1 3}$ and $\mathbf{1 4}$

\begin{tabular}{|c|c|c|c|c|c|c|c|c|c|}
\hline Position & 1 & 2 & 3 & 4 & 5 & 6 & 7 & 13 & 14 \\
\hline 2 & 170.7 & 170.2 & 165.4 & 165.5 & 165.5 & 165.4 & 165.5 & 166.2 & 166.2 \\
\hline 3 & 75.5 & 73.7 & 84.0 & 84.3 & 84.2 & 84.3 & 84.2 & 84.2 & 84.1 \\
\hline 4 & 77.1 & 76.5 & 78.7 & 78.1 & 78.7 & 78.8 & 78.8 & 78.7 & 78.6 \\
\hline $4 a$ & 130.3 & 127.5 & 111.5 & 110.8 & 110.9 & 110.8 & 110.9 & 110.8 & 110.8 \\
\hline 5 & 126.5 & 130.5 & 157.4 & 155.3 & 155.2 & 155.6 & 155.4 & 155.0 & 155.0 \\
\hline 6 & 125.3 & 124.3 & 119.3 & 121.9 & 121.6 & 122.4 & 121.1 & 121.9 & 121.9 \\
\hline 7 & 129.3 & 130.7 & 129.7 & 127.8 & 127.5 & 127.3 & 127.4 & 127.4 & 127.3 \\
\hline 8 & 116.0 & 116.1 & 107.6 & 106.9 & 106.9 & 107.1 & 106.4 & 107.0 & 107.0 \\
\hline $8 a$ & 133.4 & 135.8 & 137.5 & 134.3 & 133.6 & 134.3 & 134.1 & 134.3 & 134.2 \\
\hline $1^{\prime}$ & 131.6 & 132.4 & 128.4 & 129.0 & 128.9 & 129.1 & 129.1 & 129.0 & 129.0 \\
\hline $2^{\prime}, 6^{\prime}$ & 128.4 & 127.9 & 127.8 & 127.9 & 127.8 & 127.9 & 127.7 & 127.4 & 127.3 \\
\hline $3^{\prime}, 5^{\prime}$ & 113.9 & 114.1 & 114.5 & 114.3 & 114.3 & 114.4 & 113.9 & 114.2 & 114.2 \\
\hline $4^{\prime}$ & 159.5 & 159.3 & 160.5 & 160.1 & 160.3 & 160.2 & 160.3 & 160.2 & 160.2 \\
\hline $1^{\prime \prime}$ & & & 138.1 & 121.1 & 123.4 & 122.6 & 120.4 & 123.2 & 123.1 \\
\hline $2^{\prime \prime}$ & & & 126.8 & 135.6 & 134.4 & 131.2 & 135.5 & 134.3 & 134.3 \\
\hline $3^{\prime \prime}$ & & & 199.4 & 83.3 & 77.1 & 142.9 & 83.2 & 74.4 & 74.3 \\
\hline $4^{\prime \prime}$ & & & 26.9 & 38.5 & 30.4 & 116.7 & 39.0 & 30.9 & 31.0 \\
\hline $5^{\prime \prime}$ & & & & 26.5 & 34.2 & 18.7 & 31.2 & 33.5 & 33.5 \\
\hline $6^{\prime \prime}$ & & & & 85.8 & 34.1 & & 82.3 & 29.6 & 29.6 \\
\hline $7^{\prime \prime}$ & & & & 26.7 & 97.8 & & 26.5 & 72.7 & 72.7 \\
\hline $8^{\prime \prime}$ & & & & 71.0 & 31.1 & & 145.7 & 29.2 & 29.1 \\
\hline $9^{\prime \prime}$ & & & & 27.5 & 26.2 & & 110.1 & 26.5 & 26.5 \\
\hline $10^{\prime \prime}$ & & & & 24.4 & 16.7 & & 18.5 & 24.0 & 24.0 \\
\hline $3-\mathrm{OCH}_{3}$ & & & 59.7 & 58.9 & 58.8 & 59.0 & 58.5 & 58.9 & 58.9 \\
\hline $4^{\prime}-\mathrm{OCH}_{3}$ & 55.3 & 55.4 & 55.4 & 55.4 & 55.2 & 55.4 & 55.0 & 55.2 & 55.2 \\
\hline
\end{tabular}

Spectra taken at $150 \mathrm{MHz}$. Chemical shifts are shown with reference to $\mathrm{CDCl}_{3}$ as $77.0 \mathrm{ppm}$.

peaks from $\mathrm{H}^{\prime \prime}(\delta 1.86)$ to $\mathrm{C}^{\prime \prime}(\delta 83.3)$ and $\mathrm{C} 8^{\prime \prime}(\delta 71.0)$, from $\mathrm{H}_{3} 9^{\prime \prime}(\delta 1.24)$ to $\mathrm{C} 6 "$ ( $\left.\delta 85.8\right), \mathrm{C}^{\prime \prime}$ and $\mathrm{C} 10^{\prime \prime}(\delta 24.4)$, from $\mathrm{H}_{3} 10^{\prime \prime}(\delta 1.13)$ to $\mathrm{C}^{\prime \prime}, \mathrm{C} 8^{\prime \prime}$ and $\mathrm{C} 9^{\prime \prime}(\delta 27.5)$ and from $\mathrm{H}_{3} 7^{\prime \prime}(\delta 1.41)$ to $\mathrm{C}^{\prime \prime}$ and the olefinic carbon $\mathrm{C} 2$ " $(\delta$ 135.6) lead to a bigger partial structure $\mathrm{V}$ containing IV. The cross peak from $\mathrm{H} 7(\delta 7.35)$ to $\mathrm{Cl}^{\prime \prime}(\delta 121.1)$, from $\mathrm{H} 1^{\prime \prime}(\delta 6.77)$ to $\mathrm{C} 5(\delta$ 155.3) and from H2" $(\delta$ 6.24) to $\mathrm{C} 6(\delta$ 121.9) indicated that the partial structure $\mathrm{V}$ is attached to $\mathrm{C} 6$. Taking the remaining atoms (one hydrogen and two oxygens) and the chemical shifts of C3", C6" and C8" (bound to an oxygen) into consideration, it was concluded that $\mathrm{C}^{\prime \prime}$ and $\mathrm{C}^{\prime \prime}$ should connect to the same oxygen to form a furan ring and a hydroxy group is attached to C 8 ". Thus, the structure of $\mathbf{4}$ was elucidated to be that shown in Fig. 2, which satisfied the molecular formula and the degree of unsaturation.

Yaequinolone D (5): The molecular formula of 5 was revealed to be $\mathrm{C}_{27} \mathrm{H}_{33} \mathrm{NO}_{7}$ by HR-FAB-MS. The ${ }^{1} \mathrm{H}$ and ${ }^{13} \mathrm{C}$ NMR spectra (Tables 2 and 3) resembled those of $\mathbf{1 3}$ or $\mathbf{1 4}$ except for the carbon signal of $\mathrm{C} 7 "$. The ${ }^{13} \mathrm{C}$ NMR chemical shift of $\mathrm{C}^{\prime \prime}$ indicated the presence of the $s p^{3}$ dioxy quaternary carbon $(\delta 97.8)$, and we concluded that the hydroxy group was attached to $\mathrm{C} 77^{\prime \prime} .{ }^{1} \mathrm{H}-{ }^{1} \mathrm{H} \mathrm{COSY}$ and HMBC experiments supported the structure of $\mathbf{5}$ as shown in Fig. 2.

Yaequinolone E (6): The molecular formula of $\mathbf{6}$ was revealed to be $\mathrm{C}_{22} \mathrm{H}_{23} \mathrm{NO}_{5}$ by HR-FAB-MS. The ${ }^{1} \mathrm{H}$ and ${ }^{13} \mathrm{C}$ NMR spectra (Tables 2 and 3) resembled those of $\mathbf{3}$ except for the carbon signal of $\mathrm{C}^{\prime \prime}$. In HMBC experiment examining 6 (Fig. 2), the cross peaks from $\mathrm{H}^{\prime \prime}(\delta 6.84)$ and $\mathrm{H}_{3} 5^{\prime \prime}(\delta 1.95)$ to $\mathrm{C}^{\prime \prime}(\delta 142.9)$ and $\mathrm{C} 4 "(\delta 116.7)$ and from $\mathrm{H}_{2} 4^{\prime \prime}(\delta 5.06,5.02)$ to $\mathrm{C} 2 "\left(\delta\right.$ 131.2) and $\mathrm{C}^{\prime \prime}(\delta$ 18.7) indicated the presence of a methylene attached to $\mathrm{C}^{\prime \prime}$ instead of a ketone of $\mathbf{3}$. Thus, the structure of $\mathbf{6}$ was elucidated to be that shown in Fig. 2.

Yaequinolone F (7): The molecular formula of 7 was revealed to be $\mathrm{C}_{27} \mathrm{H}_{31} \mathrm{NO}_{6}$ by HR-FAB-MS. The ${ }^{1} \mathrm{H}$ and ${ }^{13} \mathrm{C}$ NMR spectra (Tables 2 and 3) resembled those of $\mathbf{4}$ except for the carbon signals of $\mathrm{C}^{\prime \prime}$ and $\mathrm{C} 9{ }^{\prime \prime}$. In HMBC experiments, the cross peaks from $\mathrm{H} 6^{\prime \prime}(\delta 4.46)$ to $C 9^{\prime \prime}(\delta$ 


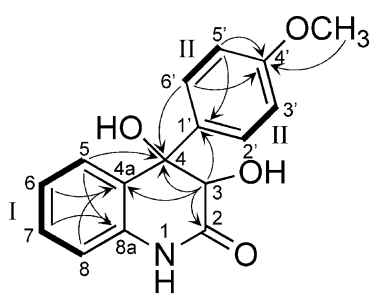

1

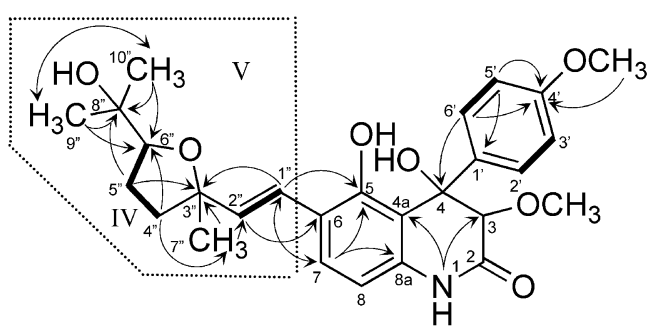

4

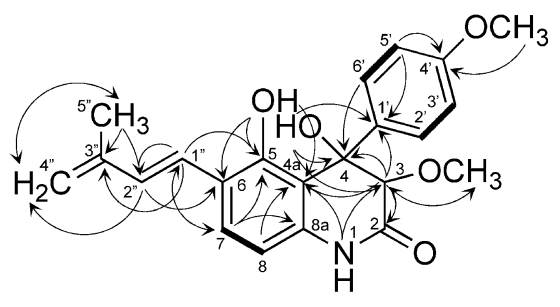

6

2
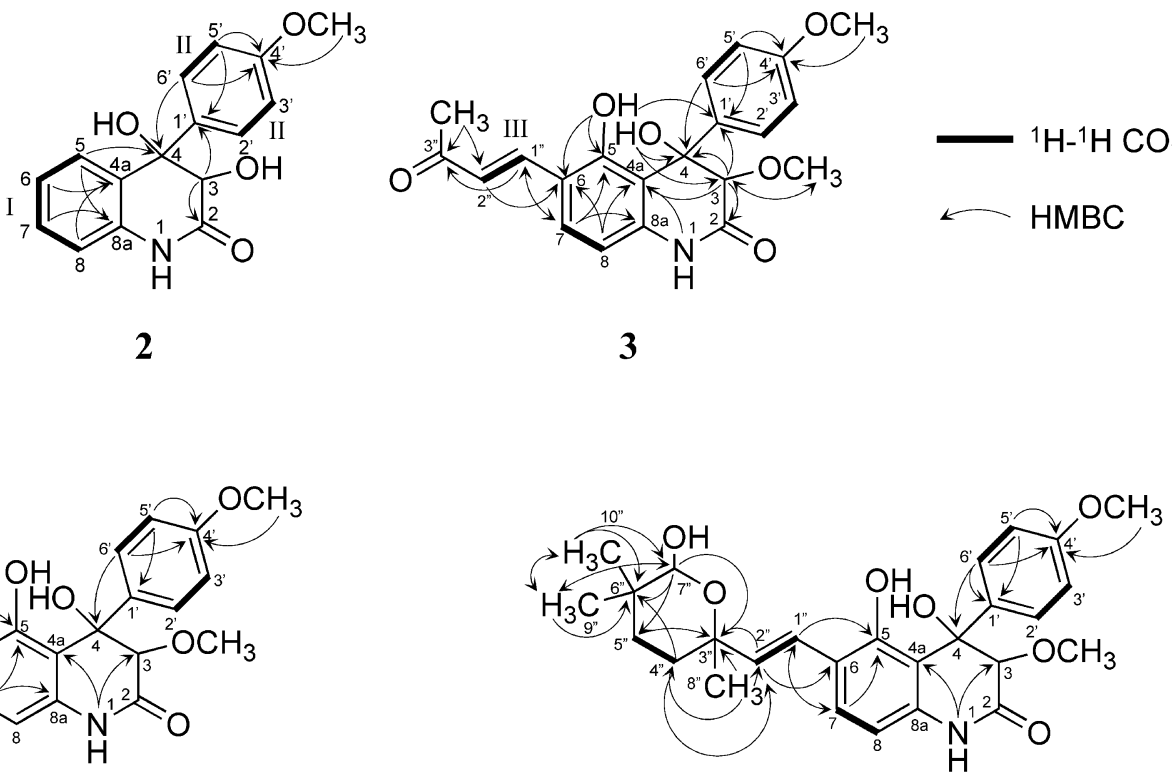

5

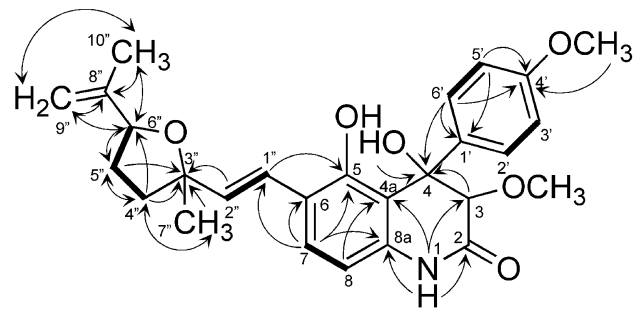

7

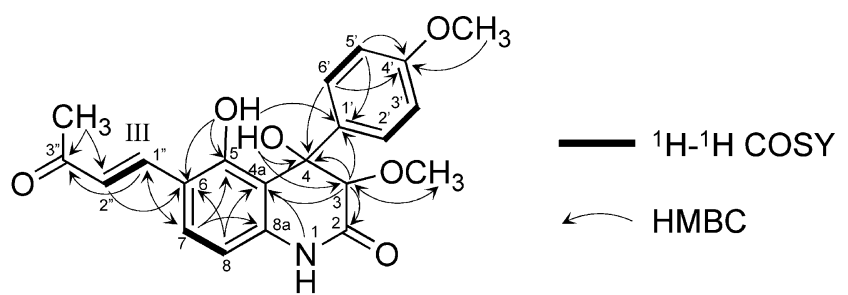

3

Fig. $2{ }^{1} \mathrm{H}^{-1} \mathrm{H}$ COSY and $\mathrm{HMBC}$ experiments of $\mathbf{1}$ to $\mathbf{7}$.

$110.1), \mathrm{H}_{3} 10^{\prime \prime}(\delta 1.75)$ to $\mathrm{C} 8^{\prime \prime}(\delta 145.7)$ and $\mathrm{C} 9^{\prime \prime}$ and from $\mathrm{H}_{2} 9^{\prime \prime}(\delta 5.08,4.82)$ to $\mathrm{C}^{\prime \prime}(\delta 82.3), \mathrm{C} 8$ " and $\mathrm{C} 10^{\prime \prime}(\delta 18.5)$ showed the presence of a methylene attached to $\mathrm{C} 8$ ". Thus, the structure of 7 was elucidated to be that shown in Fig. 2.

\section{Relative Stereochemistry of $p$-Methoxyphenyl Quinolinone Skeleton}

Compounds $\mathbf{1}$ and $\mathbf{2}$ have two chiral carbons of $\mathrm{C} 3$ and $\mathrm{C} 4$ in the quinolinone ring. Their relative stereochemistry was elucidated by NOE experiments (Fig. 3). An NOE was observed between $\mathrm{H} 3$ and $\mathrm{H} 2^{\prime}\left(\mathrm{H}^{\prime}\right)$, but the intensity of NOE in $\mathbf{2}(7.1 \%)$ was much stronger than that in $\mathbf{1}(0.75 \%)$. These results indicated that the $p$-methoxyphenyl group and $3-\mathrm{OH}$ in $\mathbf{1}$ are located on the same face of the quinolinone ring, while those in $\mathbf{2}$ are located on the opposite side. Therefore, the relative stereochemistry of $\mathbf{1}$ and $\mathbf{2}$ was determined to be $3 R^{*}, 4 S^{*}$ and $3 R^{*}, 4 R^{*}$, respectively.<smiles>COc1ccc([C@]2(O)C(=O)Nc3ccccc3C2(O)O)cc1</smiles>

1<smiles>CCN(CC)CC[C@]1(O)C(=O)Nc2ccccc2[C@]1(O)c1ccc(OC)cc1</smiles>

2

Fig. 3 NOE experiments of $\mathbf{1}$ and $\mathbf{2}$.

NOE experiments for $\mathbf{3}$ to $\mathbf{7}$ showed similar results to those for $\mathbf{2}$, indicating that the stereochemistry of their quinolinone skeleton is $3 R^{*}, 4 R^{*}$. 


\section{Discussion}

During this study we isolated 16 structurally related compounds from the culture broth of Penicillium sp. FKI-2140. Compounds $\mathbf{1 5}$ and $\mathbf{1 6}$ are diketodiazepins. Compounds 1, 2, 10 and 11 have the fundamental $p$ methoxyphenyl quinolinone skeleton, while the others have an additional isoprenyl derived (C5 or C10 unit) side chain attached to the fundamental skeleton.

Biosynthetic studies of this series of compounds have not been reported so far, but the biosynthetic pathway could be speculated to be as follows [5]. First, diketodiazepins $\mathbf{1 5}$ and $\mathbf{1 6}$ are biosynthesized from anthranilic acid and tyrosine, which are de- and re-cyclized to form the fundamental phenylquinolinones $(\mathbf{1}, \mathbf{2}, 10$ and 11). Similar cyclization was reported in the biosynthesis of a phenylquinolinic ring in fungal viridicatin $[7,8]$. Then, an isoprenyl (C5)- or geranyl (C10)-derived side chain are linked to the skeleton to form 3,6 and 12 or $4,5,7,13$ and 14, respectively. Finally, intramolecular dehydration occurs to produce $\mathbf{8}$ and $\mathbf{9}$.

Although the relative stereochemistry of the side chains in yaequinolones could not be defined, that of the quinolinone skeleton was determined by NOE experiments. Compound 1 has the $3 R^{*}, 4 S^{*}$ stereochemistry, while 2 to $\mathbf{1 2}$ have $3 R^{*}, 4 R^{*}$. In this study $\mathbf{1 3}$ and $\mathbf{1 4}$ were separated by using a chiral column, though they were originally isolated as a mixture. They were both found to have $3 R^{*}, 4 R^{*}$ stereochemistry. Thus, only $\mathbf{1}$ has different stereochemistry, probably due to racemization during cyclization from $\mathbf{1 5}$ or $\mathbf{1 6 .}$

\section{Experimental}

\section{Spectroscopic Measurements}

NMR spectra were recorded on a Varian Inova 600 spectrometer $\left({ }^{2-3} J_{\mathrm{CH}}=8 \mathrm{~Hz}\right.$ in HMBC). Chemical shifts are shown in $\delta$ values (ppm) relative to chloroform at $7.26 \mathrm{ppm}$ for ${ }^{1} \mathrm{H}$ NMR and chloroform- $d_{1}$ at $77.0 \mathrm{ppm}$ for ${ }^{13} \mathrm{C}$ NMR. FAB mass spectrometry was conducted on a JEOL JMSAX505H spectrometer. UV and IR spectra were measured with a Beckman DU640 spectrophotometer and a Horiba FT-210 Fourier transform infrared spectrometer, respectively.
Optical rotations were recorded on a JASCO model DIP181 polarimeter.

Acknowledgements We are grateful to Ms. Akiko Nakagawa, Ms. Chikako Sakabe and Ms. Noriko Sato, School of Pharmacy, Kitasato University for measurements of mass and NMR spectra. This work was supported by a grant for the 21 st Century COE Program and a grant for Scientific Research on Priority Areas (No. 16073215) from the Ministry of Education, Culture, Sports, Science and Technology, Japan

\section{References}

1. Uchida R, Imasato R, Yamaguchi $Y$, Masuma R, Tomoda H, Ōmura S. Yaequinolones, new insecticidal antibiotics produced by Penicillium sp. FKI-2140. I. Taxonomy, fermentation, isolation and biological properties. J Antibiot. 59: 646-651 (2006)

2. Uchida $R$, Imasato $R$, Shiomi $K$, Tomoda H, Ōmura $S$. Yaequinolones $\mathrm{J} 1$ and $\mathrm{J} 2$, novel insecticidal antibiotics from Penicillium sp. FKI-2140. Org Lett 7: 5701-5704 (2005)

3. He J, Lion U, Sattler I, Gollmic FA, Grabley S, Cai J, Meiners M, Schünke H, Schaumann K, Dechert U, Krohn M. Diastereomeric quinolinone alkaloids from the marinederived fungus Penicillium janczewskii. J Nat Prod 68: 1397-1399 (2005)

4. Hayashi H, Nakatani T, Inoue Y, Nakayama M, Nozaki H. New dihydroquinolone toxic to Artemia salina produced by Penicillium sp. NTC-47. Biosci Biotechnol Biochem 61: 914-916 (1997)

5. Kusano M, Koshino H, Uzawa J, Fujioka S, Kawano T, Kimura Y. Nematocidal alkaloids and related compounds produced by the fungus Penicillium cf. simplicissimum. Biosci Bootechnol Biochem 64: 2559-2568 (2000)

6. Kimura Y, Kusano M, Koshino H, Uzawa J, Fujioka S, Tani $\mathrm{K}$. Penigequinolone $\mathrm{A}$ and $\mathrm{B}$, pollen-growth inhibitors produced by Penicillium sp. NO. 410. Tetrahedron Lett 37: 4961-4964 (1996)

7. Framm J, Nover L, el-Azzouny A, Richter H, Winter K, Werner S, Luckner M. Cyclopeptin and dehydrocyclopeptin. Intermediates in the biosynthesis of cyclopeptin-viridicatin alkaloids in Penicillium cyclopium Westling. Eur J Biochem 37: 78-85 (1973)

8. Nover L, Luckner M. On the biosynthesis of cyclopenin and cyclopenol, benzodiazepine alkaloids from Penicillium cyclopium Westling. Eur J Biochem 10: 268-273 (1969) 